Research Article

Open Access

\title{
Protein Expression of DNA Damage Signaling Molecules in Patients with Oral Squamous Cell Carcinoma
}

\author{
Jigna S Joshi' 1 , Hemangini H Vora ${ }^{2}$, Nandita R Ghosh ${ }^{3}$, Jignesh V Goswami ${ }^{4}$ and Trupti Trivedi ${ }^{\text {* }}$ \\ IClinical Carcinogenesis Lab, Gujarat Cancer and Research Institute, Asarwa, Ahmedabad, India \\ 2Immunohematology Lab, Gujarat Cancer and Research Institute, Asarwa, Ahmedabad, India \\ ${ }^{3}$ Tumor biology Lab, Gujarat Cancer and Research Institute, Asarwa, Ahmedabad, India \\ ${ }^{4}$ Department of Surgical Oncology, Gujarat Cancer and Research Institute, Asarwa, Ahmedabad, India
}

\section{Article Info}

*Corresponding author:
Trupti Trivedi
Senior Scientific Officer \& In-charge
Clinical Carcinogenesis Lab
Department of Cancer Biology
The Gujarat Cancer \& Research Institute
Asarwa, Ahmedabad-380 016
India
E-mail: trupti.trivedi@gcriindia.org

Received: June 1, 2018

Accepted: July 4, 2018

Published: July 9, 2018

Citation: Joshi JS, Vora HH, Ghosh NR, Goswami JV, Trivedi TI. Protein Expression of DNA Damage Signaling Molecules in Patients with Oral Squamous Cell Carcinoma. Madridge J Oncogenesis. 2018; 2(1): 41-46. doi: $10.18689 /$ mjo-1000107

Copyright: @ 2018 The Author(s). This work is licensed under a Creative Commons Attribution 4.0 International License, which permits unrestricted use, distribution, and reproduction in any medium, provided the original work is properly cited.

Published by Madridge Publishers

\begin{abstract}
Purpose: Oral squamous cell carcinoma (OSCC) is mainly attributable to tobacco use which may cause errors in DNA synthesis leading to mutation. Eukaryotic cells have evolved the pathways to detect such damages. Disturbance in DNA damage signaling molecules might play a fundamental role in the pathogenesis of OSCC. Therefore, our aim of this study is to evaluate the protein expression of Mre11, Rad50, H2AX, 53BP1 and BRCA 1 in patients with OSCC.
\end{abstract}

Materials and Method: Protein expression of Mre11, Rad50, H2AX, 53BP1 and BRCA1 were studied immunohistochemically from paraffin embedded tumor tissues of 100 patients with OSCC. Expression was scored by modified histoscore (H-score). Data were evaluated statistically using SPSS software.

Results: Nuclear protein expression was observed for the Mre11, Rad50, H2AX and 53BP1 while cytoplasmic expression was observed for BRCA1 protein. Significant association was observed between Mre11 protein expression and nodal extension $(p=0.019), \operatorname{Rad} 50$ protein expression and advance disease stage (stage $\mathrm{I} / \mathrm{Il} ; \mathrm{p}=0.015)$, 53BP1 protein expression and buccal mucosa cancer $(p=0.045)$. Further, amongst all the studied biomarkers, Mre11 was significantly associated with reduced relapse free survival (RFS) in both univariate $(p=0.045)$ and multivariate survival $(p=0.040)$ analysis. None of the other studied DNA damage signaling molecules were associated with reduced relapse or death rate after the adjuvant therapies.

Conclusion: Our results suggests that amongst all studied signaling molecules strong expression of Mre11 protein is associated with increased recurrence rate suggesting it might be used as prognostic tool in the analysis of tumor specimen of OSCC.

Keywords: Oral squamous cell carcinoma; Mre11; Rad50; H2AX; BRCA1; 53BP1.

\section{Introduction}

High incidence of oral squamous cell carcinoma (OSCC) is attributable to high prevalence of life style habits such as smoking, chewing tobacco and high alcohol consumption which functions as a cofactor. As a result of that every cell in the body experiences DNA damages such as single stranded breaks (SSBs) and double-strand breaks (DSBs). Such damages are particularly harmful to the cell as they causes base pair mismatch which is strongly associated with cancer susceptibility [1]. DNA damage can 
have deleterious effects, as it interferes with DNA replication and transcription and ultimately results in mutations and chromosomal aberrations. In dividing cells, if DNA damages are not repaired, causes errors during DNA synthesis leading to mutations that can give rise to cancer. Thus, individuals with an inherited impairment in DNA repair capability are often at increased risk of cancer [2].

Previously, we have identified a mediator of DNA damage check point protein (MDC1) as a significant predictor of OSCC [3]. Therefore, we hypothesized that deficiencies in DNA damage signalling molecules might play fundamental roles in the pathogenesis of OSCC. These include several sensor proteins like Mre11, Rad50, H2AX, 53BP1 and BRCA1. Mre11 is a core protein of the MRN complex, co-localize at the site of DNA DSBs along with Nibrin and Rad50 and forms distinctive foci upon ionizing radiation [4-6]. Rad50 acts as a bridge at the junction of DNA DSBs and facilitates the recognition and processing of broken DNA ends by Mre11 exonuclease activity and holds the broken strand of DNA together during the repairing process [4]. Earlier, in head \& neck cancers, Rad50 has been explored as a potential therapeutic target [7]. When mutation occurs in Rad50 gene it leads to the formation of an abnormally small, non-functional version of Rad50 protein. Further, one of the earliest steps in the cellular response to DSBs is the phosphorylation of histone $H 2 A X$ at serine 139 , resulting in $\mathrm{YH} 2 \mathrm{AX}$ [8]. During 30 minutes after DSB formation, large numbers of $\mathrm{Y}-\mathrm{H} 2 \mathrm{AX}$ molecules form in the chromatin around the break site, creating a focus where proteins involved in DNA repair accumulate [9]. 53BP1 is known to be an activator of p53 [10]. However, 53BP1 also has p53 independent functions, and deletion of both 53BP1 and p53 has a synergistic effect on tumor development and was considered to induce apoptosis by activating tumor-suppressor gene p53 [11] but recently, it has been found that 53BP1 plays a critical role in the DNA damage repair to maintain cell genomic stability and in prevention of tumor development $[12,13]$. BRCA1 is tumor suppressor and genome guardian protein [14]. It participates in processes such as cell cycle checkpoint; activation; transcription regulation and DNA repair [15]. Nuclear BRCA1 functions in transcriptional regulation, DNA damage response, repair and cell proliferation [16]. When localized in the cell cytoplasm triggers apoptosis via a p53-independent mechanism in human breast cancer cells $[17,18]$. BRCA1 gets fused to RAD51 and gets phosphorylated. This interaction between BRCA1 and RAD51 suggests a possible participation in the detection and recombination of DSBs.

On the basis of this information the aim of the present study was to investigate the association between the expression of Mre11, Rad50, H2AX, 53BP1 and BRCA1 status and various clinicopathological parameters in cohort of patients with OSCC and to evaluate the prognostic relevance of all variables in terms of survival.

\section{Material and Methods Patients}

A total of 100 previously untreated patients with histolpathologically confirmed OSCC of tongue and buccal mucosa enrolled at The Gujarat Cancer \& Research Institute (GCRI) between year 2011 and 2014 were included in the study. Written consent of the patients prior to surgery was obtained. Clinical and pathological details were documented in a predesigned performa; which included age, gender and anatomic site, clinical TNM staging (tumor, node, and metastasis classification of malignant tumors according to American Joint Committee on Cancer), nodal status and histopathological differentiation. Out of 100 OSCC patients, 20\% (20/100) patients had stage I, 22\% (22/100) of patients had stage II, 18\% (18/100) patients had stage III and 40\% (40/100) patients had stage IV disease in current study. Postoperative treatment included radiotherapy and chemotherapy, instituted by the radiotherapy and medical oncology units of the GCRI, respectively (Table 1).

\section{Follow-up study}

Follow-up status of the patients was verified and regularly updated from the patients' case files maintained at the GCRI. Patients were monitored for a minimum period of 24 months from the date of diagnosis for survival analysis. Out of 100, only 90 patients could be followed for a minimum period of 24 months or died within that period were included for overall survival (OS) analysis out of which 43\% (39/90) patients died within that period. While, out of them 12 patients who died because of the persistent disease within 24 months were omitted for relapse free survival (RFS) analysis. Thus, RFS was carried out in total 78 patients. Out of them 41\% (32/78) patients developed recurrence within that period. RFS was expressed as the number of months from the date of surgery to the loco-regional relapse (Table 1).

Table 1. Clinicopathological characteristics of OSCC patients included in the study

\begin{tabular}{|l|c|}
\hline Parameters & Total patients N (\%) \\
\hline & $100(100)$ \\
\hline Age (Range: 21-81 years) & \\
Median : 45 Years & $47(47)$ \\
$<45$ & $53(53)$ \\
$\geq 45$ & \\
\hline Gender & $75(75)$ \\
Male & $25(25)$ \\
\hline Female & \\
\hline Anatomic site & $61(61)$ \\
Tongue & $39(39)$ \\
Buccal mucosa & \\
\hline Tobacco habit & $14(14)$ \\
Absent & $86(86)$ \\
Present & \\
\hline Tumor size & $71(71)$ \\
\hline $\mathrm{T} 1 / \mathrm{T} 2$ & $29(29)$ \\
\hline T3/T4 & \\
\hline Tumor stage & $20(20)$ \\
I $\left(\mathrm{T}_{1} \mathrm{~N}_{0} \mathrm{M}_{0}\right)$ & $22(22)$ \\
II (T $\left.\mathrm{N}_{0} \mathrm{M}_{0}\right)$ & $18(18)$ \\
III ( $\left.\mathrm{T}_{1-3} \mathrm{~N}_{0-1} \mathrm{M}_{0}\right)$ & $40(40)$ \\
IV ( $\left.\mathrm{T}_{1-4} \mathrm{~N}_{0-3} \mathrm{M}_{0-1}\right)$ & \\
\hline Nodal status & $59(59)$ \\
Negative & $41(41)$ \\
Positive & \\
\hline Histologic grade & $50(50)$ \\
Well differentiated & $50(50)$ \\
Moderate/Poorly differentiated & \\
\hline Treatment & $100(100)$ \\
Surgery (s) followed by & $54(54)$ \\
RT & $30(30)$ \\
RT $+C T$ & \\
\hline
\end{tabular}




\begin{tabular}{|l|c|}
\hline Follow-up status (OS) & $90(100)$ \\
Alive & $51(57)$ \\
Dead & $39(43)$ \\
\hline Follow-up status (RFS) & $78(100)$ \\
No recurrence & $46(59)$ \\
Recurrence & $32(41)$ \\
\hline
\end{tabular}

\section{Immunohistochemistry (IHC)}

Paraffin embedded section of OSCC tumor tissues $(\mathrm{N}=100)$ with $4-\mu \mathrm{m}$ thickness were collected on 3-aminopropyletriethoxy silane - coated glass slides. Immunostaining was performed on sections as described previously [19]. Briefly, sections were deparaffinized in xylene and rehydrated in graded alcohol. The sections were incubated with hydrogen peroxide solution prepared in methanol for 15 minutes to quench the endogenous peroxidase activity and then cooked for 10 minutes with $10 \mathrm{mM}$ tri-sodium citrate buffer $(\mathrm{pH}-6.0)$ in boiling water bath for antigen retrieval. Thereafter, slides were incubated with primary antibodies at $4^{\circ} \mathrm{C}$ overnight in a moist chamber. Before applying primary antibody, non specific conjugations were blocked using rabbit specific HRP/DAB (ABC) detection IHC kit (Abcam, Cambridge, UK). Primary antibodies with the appropriate dilution used in the study are depicted in Table 2. Antibody detection was achieved using 3, $3^{\prime}$-diaminobenzidin (DAB) as chromogen, counter stained with Mayer's haematoxylin, dehydrated in ethanol, mounted in dibutyl phthalate xylene (DPX), cover slipped and then observed under light microscope. As a positive control tissue section with intense staining for the given marker was included with each staining procedure while, for negative control, the primary antibody was replaced with tris-buffered saline.

Table 2. Primary antibodies used for expression of DNA damage signaling molecule

\begin{tabular}{|l|l|l|l|}
\hline Antigen & Primary antibody & Dilution & Staining pattern \\
\hline Mre11 & $\begin{array}{l}\text { Rabbit monoclonal, clone:31H4 } \\
\text { (Cell signaling technology, 4847) }\end{array}$ & $1: 50$ & Nuclear \\
\hline Rad50 & $\begin{array}{l}\text { Mouse monoclonal, clone:13B3 } \\
\text { (Genetex, GTX70228) }\end{array}$ & $1: 50$ & Nuclear \\
\hline H2AX & $\begin{array}{l}\text { Rabbit monoclonal, clone: EPR895 } \\
\text { (Genetex, GTX62983) }\end{array}$ & $1: 1000$ & Nuclear \\
\hline BRCA1 & $\begin{array}{l}\text { Mouse monoclonal, clone:GLK-2 } \\
\text { (Santa cruz biotechnology, sc-56030) }\end{array}$ & $1: 10$ & Cytoplasmic \\
\hline 53BP1 & $\begin{array}{l}\text { Rabbit polyclonal } \\
\text { (Invitrogen, A14034) }\end{array}$ & $1: 200$ & Nuclear \\
\hline
\end{tabular}

\section{Interpretation of IHC}

All the sections were scored separately by two individual observers in a blinded fashion. Sections were scored using modified Histo-score $(\mathrm{H}$ - score) method in which all the sections were scored on the basis of percentage of positive cells and staining intensity [19]. Thereafter, the staining was divided between weak and strong protein expressing groups according to the median $\mathrm{H}$-score value of each of the studied biomarker which was 30, 45, 160, 60 and 120 for Mre11, Rad50, H2AX, BRCA1 and 53BP1, respectively. Protein expression below median $\mathrm{H}$-score was interpreted as 'weak' protein expression and above median $\mathrm{H}$-score as 'strong' protein expression.

\section{Statistical analysis}

All statistical data were analyzed by SPSS software version 20 . An association between protein expression and clinicopathological parameters were calculated using two-tailed chi square test. Correlation between two parameters was calculated using Spearman's correlation coefficient ( $r$ ). Estimates of univariate disease-free survival (RFS) and overall survival (OS) were calculated using the Kaplan-Meier method and the differences were assessed by the log-rank test. Multivariate survival analysis was carried out using Cox regression forward step-wise model. All $P$ values were two-tailed and a $<0.05$ level was considered statistically significant.

\section{Results}

\section{Incidence of protein expression and correlation with clinicopathological parameters}

In the set of 100 OSCC patients of the current study, the incidence of protein expression of DNA damage signaling molecules was at following rates; Mre $1168 \%$ (68/100), Rad50 87\% (87/100), BRCA1 86\% (86/100) while for H2AX and 53BP1 it was $100 \%(100 / 100)$. Amongst studied molecules, nuclear protein expression was observed for Mre11, Rad50, H2AX and 53BP1 while cytoplasmic protein expression was observed for BRCA1 in patients with OSCC (Figure 1).
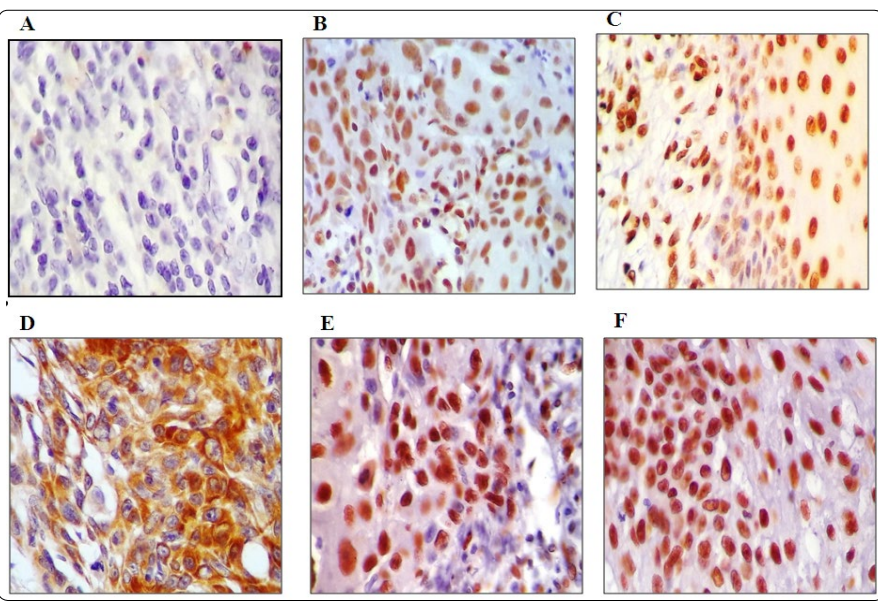

Figure 1. Representative images of $\mathrm{IHC}$ staining of A) Negative staining, B) Mre11; Nuclear staining, C) Rad 50; Nuclear staining, D) H2AX; Nuclear staining, E) BRCA1; Cytoplasmic staining, F) 53BP1; Nuclear staining in patients with OSCC (original $X 40 \mathrm{x}$ )

\section{Correlation between biomarker expression and clinicopathological parameters}

Clinicopathological characteristics of the OSCC patients included in the present study was age, gender, site of tumor, habit, tumor size, clinical stage, nodal status and tumor differentiation. Strong expression of Mre11 protein was significantly higher in patients with nodal extension $(p=0.019$; Figure $2 \mathrm{~A}$ ) whereas protein expression of Rad 50 was significantly higher in patients with advanced stage disease $(p=0.015$; Figure 2B). Strong expression of 53BP1 protein was significantly higher in patients with buccal mucosa cancer as compared to patients with tongue carcinoma ( $p=0.045$; Figure $2 C$ ). However, neither strong nor weak expression of H2AX, BRCA1 was associated with any of the clinicopathological parameters mentioned above. Protein expression of combined DNA damage signaling molecule analysis results are depicted in Table 3, which indicated that Rad50 was significantly positively correlated with H2AX $(p=0.008)$ and 53BP1 $(p=0.024)$. While, H2AX was 
significantly positively correlated with 53BP1 $(p=0.001)$. However, expression of Mre11 protein expression did not show any significant correlation with protein expression of other studied DNA damage signaling molecules.

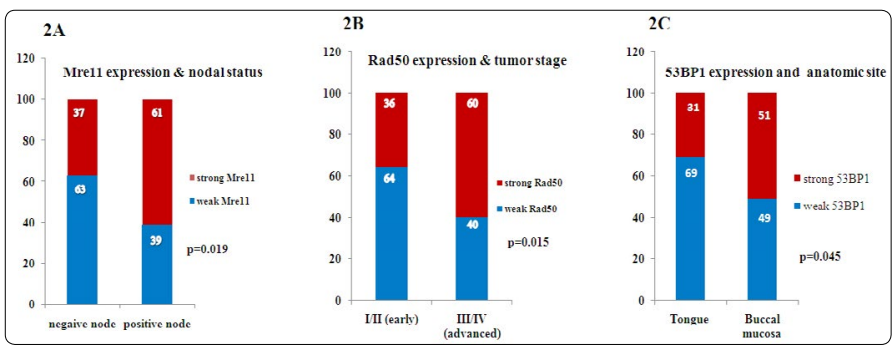

Figure 2. Representative bar chart showing correlation of protein expression with clinicopathological parameters A) Mre11 protein expression with nodal status, B) Rad 50 protein expression with tumor stage, C) 53BP1protein expression with anatomic site

Table 3. Intercorrelation of DNA damage signaling molecules in patients with OSCC

\begin{tabular}{|l|c|l|l|l|l|}
\hline \multicolumn{2}{|c|}{} & \multicolumn{1}{c|}{ Mre11 } & \multicolumn{1}{c|}{ Rad50 } & H2AX & BRCA1 \\
\hline \multirow{2}{*}{ Rad50 } & $\mathrm{r}$ & +0.060 & & & \\
\cline { 2 - 6 } & $\mathrm{p}$ & 0.552 & & & \\
\hline \multirow{2}{*}{ H2AX } & $\mathrm{r}$ & +0.113 & +0.263 & & \\
\cline { 2 - 6 } & $\mathrm{p}$ & 0.263 & $0.008^{*}$ & & \\
\hline \multirow{2}{*}{ BRCA1 } & $\mathrm{r}$ & -0.105 & +0.161 & +0.049 & \\
\cline { 2 - 6 } & $\mathrm{p}$ & 0.297 & 0.111 & 0.625 & \\
\hline \multirow{2}{*}{ 53BP1 } & $\mathrm{r}$ & +0.110 & +0.226 & +0.341 & +0.085 \\
\cline { 2 - 6 } & $\mathrm{p}$ & 0.277 & $0.024^{*}$ & $0.001^{*}$ & 0.402 \\
\hline
\end{tabular}

*statistically significant

\section{Survival analysis}

Univariate Kaplan-Meier survival analysis revealed that patients with strong expression of Mre11 protein had a significant reduced RFS ( $p=0.045$; Table 4; Figure 3) whereas none of the other studied DNA damage signaling molecules were associated with reduced relapse. However, Mre11 failed to show any significant association with overall survival (Figure 4). At the same time all of the studied biomarker Mre11, Rad50, BRCA1, H2AX and 53BP1 failed to show any significant association with shorter OS in patients with OSCC. However, multivariate survival analysis by Cox regression forward step wise model showed Mre11 as a significant independent prognosticator in predicting reduced relapse rate in patients with $\operatorname{OSCC}(B=0.764, \mathrm{HR}=2.147, \mathrm{p}=0.040)$.

Table 4. Univariate relapse free survival analysis of DNA damage signaling molecules using Kaplan-Meier survival function in patients with OSCC

\begin{tabular}{|c|c|c|c|c|c|}
\hline Variables & $\mathrm{N}=78$ & Patients Relapsed N (\%) & Log-rank & df & $p$ \\
\hline $\begin{array}{l}\text { Mre-11 } \\
\text { Weak } \\
\text { Strong }\end{array}$ & $\begin{array}{l}37 \\
41\end{array}$ & $\begin{array}{l}11(30) \\
21(51)\end{array}$ & 4.006 & 1 & 0.045 \\
\hline $\begin{array}{l}\text { Rad-50 } \\
\text { Weak } \\
\text { Strong }\end{array}$ & $\begin{array}{l}38 \\
40\end{array}$ & $\begin{array}{l}15(39) \\
17(42)\end{array}$ & 0.091 & 1 & 0.763 \\
\hline \begin{tabular}{|l|} 
H2AX \\
Weak \\
Strong \\
\end{tabular} & $\begin{array}{l}44 \\
34 \\
\end{array}$ & $\begin{array}{l}17(39) \\
15(44)\end{array}$ & 0.298 & 1 & 0.585 \\
\hline \begin{tabular}{|l|} 
BRCA1 \\
Weak \\
Strong
\end{tabular} & $\begin{array}{l}44 \\
34 \\
\end{array}$ & $\begin{array}{l}19(43) \\
13(38)\end{array}$ & 0.183 & 1 & 0.669 \\
\hline $\begin{array}{l}\text { 53BP1 } \\
\text { Weak } \\
\text { Strong }\end{array}$ & $\begin{array}{l}50 \\
28\end{array}$ & $\begin{array}{l}21(42) \\
11(39)\end{array}$ & 0.076 & 1 & 0.783 \\
\hline
\end{tabular}

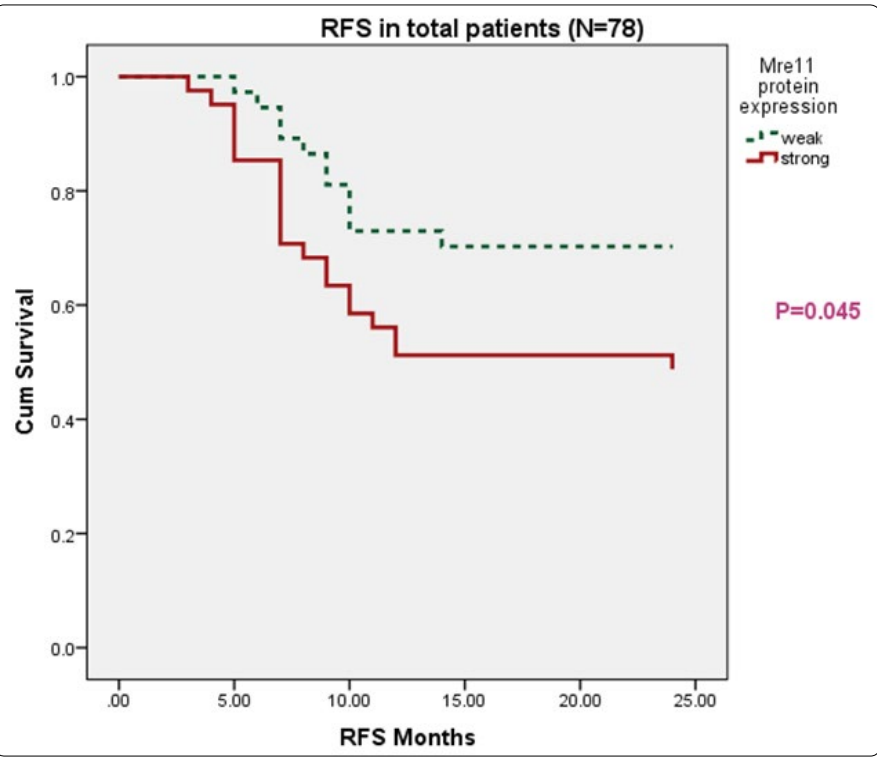

Figure 3: Kaplan-Meier survival curve for RFS in total OSCC patients $(\mathrm{N}=78)$ with Mre11 expression. Expression of strong Mre11 was significantly related to high incidence of disease relapse than those with weak Mre11 expression in total OSCC patients

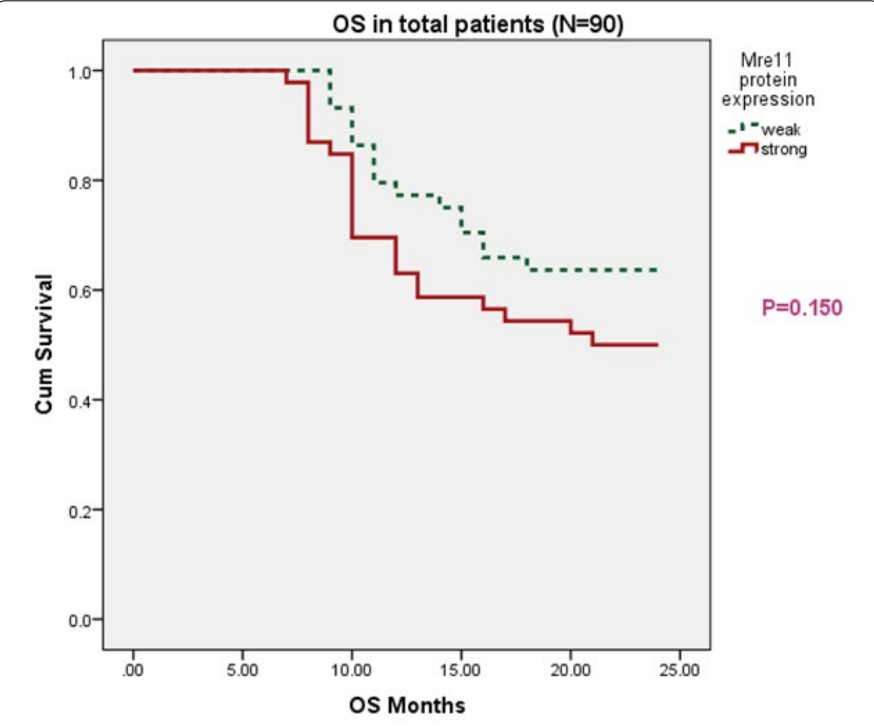

Figure 4. Kaplan-Meier survival curve for OS in total OSCC patients $(\mathrm{N}=90)$ with Mre11 expression. Expression of Mre11 failed to show any significant association with overall survival

\section{Survival analysis in relation to treatment offered}

Kaplan-Meier univariate survival analysis did not show any significant correlation of protein expression of studied DNA damage signaling molecules with RFS or OS when treated with surgery followed by either radiotherapy or chemo-radiotherapy in patients with OSCC (data not shown).

\section{Discussion}

Numerous factors are thought to be involved in DNA damage signalling, processing and repair. However, present study evaluated clinical significance of DNA damage sensor molecules such as Mre11, Rad50, H2AX, BRCA1 and 53BP1 and correlated with various clinicopathological parameters and analyzed its role in the disease outcome. In the present study, a significant high incidence of strong Mre11 protein expression 
was found in patients with lymphnode positivity than patients with lymphnode negativity indicating its association with aggressive tumor behavior. Additionally, in patients with serous ovarian cancer also, a significant high expression of Mre11 was noted in moderately differentiated tumors [20]. In current study, a significant high incidence of strong Rad50 protein expression was found in patients with advanced stage (stage III/IV) disease indicating its expression increases with disease advancement. In accordance, Ali-Fehmi et al observed an association of Rad50 protein expression with advanced disease stage in patients with ovarian cancer [21]. However, BRCA1 protein expression was not significantly correlated with any of the clinicopathological parameters in current study. In serous ovarian cancer, strong BRCA1 protein expression was significantly correlated with advanced stage disease and suggested its utility as prognostic factor in analysis of tumor biopsies and in determination of circulating tumor cells [21]. Further, a significant high incidence of strong 53BP1 protein expression was observed in patients with buccal mucosa cancer suggested an association of 53BP1 expression with excessive DNA damage to buccal mucosa due to longer exposure of tobacco to the buccal mucosa as compared to tongue. In lung adenocarcinoma, 53BP1 was correlated with advanced tumor stage, habit of cigarette smoking and lymphovascular invasion reflecting its association with increased tumor cell growth, metastasis and poor prognosis [22].

Univariate survival analysis by Kaplan-Meier revealed that strong Mre11 protein expression was significantly associated with high incidence of disease relapse in patients with OSCC. On the other hand, few studies on Mre11 expression have suggested an association of high Mre11 expression with improved survival rate in patients with colorectal cancer, breast cancer and bladder cancer [23,24]. Such discrepancy in the results might be because of difference in cell morphology, scoring method, patient inclusion criteria and treatment and geographical difference of conducted study. It has been also observed that germ line mutations in Mre11 complex genes lead to hereditary susceptibility to breast and/or ovarian cancer development which may play a role in other cancers too [25]. While, univariate survival analysis failed to show significant difference in incidence of disease relapse and death with Rad50, BRCA1 protein expression in OSCC patients which might be because of the either mutation in Rad50 gene or the activation of apoptotic pathway in which DSB repair pathways are blocked. Additionally, Rad50 is associated with several proteins such as BRCA1, ATM and CHK2 responsible for the hereditary susceptibility to ovarian and breast cancer development [25]. The present study did not show prognostic significance of the H2AX on disease relapse and death in OSCC patients. Further, a contradictory study showed that a significant reduced OS was observed in OSCC patients with positive expression of $\mathrm{YH} 2 \mathrm{AX}$ protein [26]. The $\mathrm{\gamma H} 2 \mathrm{AX}$ also did not show significant association with disease outcome in patients with colorectal cancer, however, a tendency of worse survival was observed in those patients who had loss of $\mathrm{yH} 2 \mathrm{AX}$ and underwent the preoperative radiotherapy suggesting that DSB repair deficient tumors were radioresistant [27]. Further, higher levels of $\mathrm{\gamma H} 2 \mathrm{AX}$ proved as a significant predictor for reduced OS in patients with non-small cell lung cancer, triple negative breast cancer and in endometrial cancer [28]. The possible reason of such difference in finding could be due to the phosphorylation of $\mathrm{H} 2 \mathrm{AX}$ which occurs only after the development of DNA DSBs [26]. Further, Chen et al reported BRCA1 in 17 breast tumors and these tumors exhibited cytoplasmic expression of BRCA1 suggested such aberrant staining pattern could be due to the intragenic mutation which ultimately leads to the loss of function of BRCA1 protein in patients with breast cancer [29]. In current study, 53BP1 protein expression did not show any significant correlation with RFS and OS in patients with OSCC. In pancreatic cancer, 53BP1 expression was not found to be correlated with various clinicopathological parameters and patients' survival. However, low expression of 53BP1 protein expression was found to modify the prognostic value of other predictive factors of pancreatic cancer such as level of CA 19-9 and lymphnode ratio (LNR) in such a way that high CA 19-9 and high LNR were associated with worse $O S$ in pancreatic cancer while, with high 53BP1, LNR and CA19-9 were no longer associated with OS [30].

In relation to treatment, Mre11, Rad50, H2AX, BRCA1 and 53BP1 protein expression failed to demonstrate reduced relapse or death rate in subgroup of patients treated with surgery alone, surgery followed by radiotherapy and surgery followed by chemo-radio therapy (data not shown). Further, when these sensor molecules were correlated with each other, it was observed that, Mre11 did not show any significant correlation with any of the sensor molecule of the DDR pathway. A significant positive correlation was noted of Rad50 with $\mathrm{H} 2 \mathrm{AX}$ and $53 \mathrm{BP} 1$ while, $\mathrm{H} 2 \mathrm{AX}$ was significantly positively correlated with 53BP1, indicating that activation of any of the MRN complex molecule (Mre11/Rad50/Nibrin) may lead to initiation of further repair cascade.

To conclude, by profiling key signaling molecules of DNA damage repair (DDR) pathway in OSCC patients we have demonstrated that protein expression of Mre11 and Rad50 are strongly associated with disease advancement in OSCC. Further, strong expression of Mre11 protein is associated with increased recurrence rate suggesting their potential utility as prognostic tool in the analysis of tumor specimen. Moreover, as OSCC represents an especially lethal cancer with higher recurrence rate and limited therapeutic options, we believe that these association studies further underpin the DDR pathway as a novel area of potential therapeutic intervention for OSCC.

\section{Acknowledgement}

Authors are thankful to the Gujarat Cancer Society \& The Gujarat Cancer Research Institute for providing financial support for the fulfillment of this study.

\section{References}

1. Van Gent DC, Hoeijmakers JH, Kanaar R. Chromosomal stability and the DNA double-stranded break connection. Nat Rev Genet. 2001; 2(3): 196206. doi: $10.1038 / 35056049$ 
2. Bernstein C, Bernstein H, Payne CM, Garewal H. DNA repair/pro-apoptotic dual role proteins in five major DNA repair pathways: fail-safe protection against carcinogenesis. Mutat Res. 2002; 511(2): 145-178. doi: 10.1016/ S1383-5742(02)00009-1

3. Dave JH, Vora HH, Ghosh NR, Trivedi TI. Mediator of DNA damage checkpoint protein 1 (MDC1) as a prognostic marker for patients with oral squamous cell carcinoma. J Oral Pathol Med. 2017; 46(4): 253-258. doi: 10.1111/jop. 12558

4. Assenmacher N, Hopfner KP. MRE11/RAD50/NBS1: complex activities. Chromosoma. 2004; 113(4): 157-166. doi: 10.1007/s00412-004-0306-4

5. Shrivastav $M$, De Haro LP, Nickoloff JA. Regulation of DNA double-strand break repair pathway choice. Cell Res. 2008; 18(1): 134-147. doi: 10.1038/ cr.2007.111

6. Flores-Pérez A, Rafaelli LE, Ramírez-Torres N, Aréchaga-Ocampo E, Frías $S$, Sánchez $\mathrm{S}$, et al. RAD50 targeting impairs DNA damage response and sensitizes human breast cancer cells to cisplatin therapy. Cancer Biol Ther. 2014; 15(6): 777-788. doi: 10.4161/cbt.28551

7. Figures MR, Wobb J, Araki K, Liu T, Xu L, Zhu H, et al. Head and neck squamous cell carcinoma targeted chemosensitization. Otolaryngol Head Neck Surg. 2009; 141(2): 177-183. doi: 10.1016/j.otohns.2009.04.024

8. Rogakou EP, Nieves-Neira W, Boon C, Pommier Y, Bonner WM. Initiation of DNA fragmentation during apoptosis induces phosphorylation of H2AX histone at serine 139. J Biol Chem. 2000; 275(13): 9390-9395.

9. Gorgoulis VG, Vassiliou LV, Karakaidos $P$, Zacharatos $P$, Kotsinas $A$, Liloglou T, et al. Activation of the DNA damage checkpoint and genomic instability in human precancerous lesions. Nature. 2005; 434(7035): 907913. doi: $10.1038 /$ nature03485

10. Wang B, Matsuoka S, Carpenter PB, Elledge SJ. 53BP1, a mediator of the DNA damage checkpoint. Science. 2002; 298(5597): 1435-1438. doi: 10.1126/science. 1076182

11. Morales JC, Franco S, Murphy MM, Bassing CH, Mills KD, Adams MM, et al. 53BP1 and p53 synergize to suppress genomic instability and lymphomagenesis. Proc Natl Acad Sci USA. 2006; 103(9): 3310-3315. doi: 10.1073/pnas.0511259103

12. Cao $L$, Xu X, Bunting SF, Liu J, Wang RH, Cao LL, et al. A selective requirement for $53 \mathrm{BP} 1$ in the biological response to genomic instability induced by Brca1 deficiency. Mol Cell. 2009; 35(4): 534-541. doi: 10.1016/j. molcel.2009.06.037

13. Rybanska-Spaeder I, Reynolds TL, Chou J, et al. 53BP1 is limiting for NHEJ repair in ATM-deficient model systems that are subjected to oncogenic stress or radiation. Mol Cancer Res. 2013; 11(10): 1223-1234. doi: 10.1158/1541-7786.MCR-13-0252-T

14. Santivasi WL, Wang $H$, Wang $T$, Yang $Q$, Mo X, Brogi $E$, et al. Association between cytosolic expression of BRCA1 and metastatic risk in breast cancer. Br J Cancer. 2015; 113(3): 453-459. doi: 10.1038/bjc.2015.208

15. Somasundaram K. Breast cancer gene 1 (BRCA1): role in cell cycle regulation and DNA repair-perhaps through transcription. J Cell Biochem. 2003; 88(6): 1084-1091. doi: 10.1002/jcb.10469

16. Yang ES, Xia F. BRCA1 16 years later: DNA damage-induced BRCA1 shuttling. FEBS J. 2010; 277(15): 3079-3085. doi: 10.1111/j.1742-4658.2010.07734.x

17. Rakha EA, El-Sheikh SE, Kandil MA, El-Sayed ME, Green AR, Ellis IO. Expression of BRCA1 protein in breast cancer and its prognostic significance. Hum Pathol. 2008; 39(6): 857-865. doi: 10.1016/j.humpath.2007.10.011
18. Jiang J, Yang ES, Jiang G, Nowsheen $S$, Wang $H$, Wang $T$, et al. p53Dependent BRCA1 nuclear export controls cellular susceptibility to DNA damage. Cancer Res. 2011; 71(16): 5546-5557. doi: 10.1158/0008-5472. CAN-10-3423

19. Dave $\mathrm{JH}$, Vora HH, Trivedi TI, Ghosh NR. Nibrin expression in oral squamous cell carcinoma: association with clinicopathological parameters. J Cancer Metastasis Treat. 2016; 2: 436-442. doi: 10.20517/2394-4722.2015.82

20. Ye Q, Chen L, Yin X, Liu Y, Ji Q, Zhao E. Development of Serous Ovarian Cancer is Associated with the Expression of Homologous recombination Pathway Proteins. Pathol Oncol Res. 2014; 20(4): 931-938. doi: 10.1007/ s12253-014-9776-8

21. Ali-Fehmi R, Chatterjee M, Ionan A, Levin NK, Arabi H, Bandyopadhyay S, et al. Analysis of the expression of human tumor antigens in ovarian cancer tissues. Cancer Biomark. 2010; 6(1): 33-48. doi: 10.3233/CBM2009-0117

22. Lai TC, Chow KC, Lin TY, Chiang IP, Fang HY, Chen CY, et al. Expression of 53BP1 as a cisplatin-resistant marker in patients with lung adenocarcinomas. Oncol Rep. 2010; 24(2): 321-328.

23. Gao J, Zhang H, Arbman G, Sun XF. RAD50/MRE11/NBS1 proteins in relation to tumour development and prognosis in patients with microsatellite stable colorectal cancer. Histol Histopathol. 2008; 23(12): 1495-1502. doi: 10.14670/HH-23.1495

24. Choudhury A, Nelson LD, Teo MT, Chilka S, Bhattarai S, Johnston CF, et al. MRE11 expression is predictive of cause-specific survival following radical radiotherapy for muscle-invasive bladder cancer. Cancer Res. 2010; 70(18): 7017-7026. doi: 10.1158/0008-5472.CAN-10-1202

25. Heikkinen $K$, Karppinen $S$, Soini $Y$, Mäkinen $M$, Winqvist R. Mutation screening of Mre11 complex genes: indication of RAD50 involvement in breast and ovarian cancer susceptibility. J Med Genet. 2003; 40(12): e131. doi: $10.1136 / j m g \cdot 40.12 . e 131$

26. Oliveira-Costa JP, Oliveira $L R$, Zanetti $R$, Zanetti $J S$, da Silveira GG, Chavichiolli Buim ME, et al. BRCA1 and $\mathrm{YH} 2 \mathrm{AX}$ as independent prognostic markers in oral squamous cell carcinoma. Oncoscience. 2014; 1(5): 383391. doi: 10.18632 /oncoscience. 47

27. Beggs AD, Domingo E, McGregor M, Presz $M$, Johnstone $E$, Midgley $R$, et al. Loss of expression of the double strand break repair protein ATM is associated with worse prognosis in colorectal cancer and loss of Ku70 expression is associated with CIN. Oncotarget. 2012; 3(11): 1348-1355. doi: 10.18632/oncotarget.694

28. Matthaios D, Foukas PG, Kefala M, Hountis P, Trypsianis $G$, Panayiotides $I G$, et al. $\gamma-H 2 A X$ expression detected by immunohistochemistry correlates with prognosis in early operable non-small cell lung cancer. Onco Targets Ther. 2012; 5: 309-314. doi: 10.2147/OTT.S36995

29. Chen $Y$, Chen CF, Riley DJ, Allred DC, Chen PL, Von Hoff D, et al. Aberrant Subcellular Localization of BRCA1 in Breast Cancer. Science. 1995; 270(5237): 789-791.

30. Ausborn NL, Wang T, Wentz SC, Washington MK, Merchant NB, Zhao Z, et al. 53BP1 expression is a modifier of the prognostic value of lymph node ratio and CA 19-9 in pancreatic adenocarcinoma. BMC Cancer. 2013; 13: 155 . doi: $10.1186 / 1471-2407-13-155$ 